\title{
Hitting Reply: A Qualitative Study to Understand Student Decisions to Respond to Online Discussion Postings
}

\author{
Diane D. Chapman, Julia Storberg-Walker, and Sophia J. Stone \\ North Carolina State University
}

Providing tools for dialogue exchange does not ensure that students will respond to teammate postings or that online groups will grow in cohesiveness (Murphy, 2004). Students decide whether or not to reply, and it is increasingly important to understand how students make these decisions due to the increase in distance education, millenials, and asynchronous teamwork in the workplace. This exploratory qualitative study was based on an interpretivist philosophy to understand how students 'hit reply.'

Keywords: Collaboration/Teaming and Leadership, E-learning/Online Learning/ Distance Education

Both popular and scholarly press focusing on online teaching contain research-based strategies for facilitating online asynchronous communication. Researchers have proposed ways to make learning spaces conducive for discussion and practitioners have developed strategies for evoking student participation online. Literature includes the study of participation rates and patterns (Hara, Bonk \& Angeli, 2000), the application of social, cognitive, and teaching presence research to assessing online discussion (Pelz, 2004), and learning strategies that facilitate learning in asynchronous discussions (Kanuka \& Garrison, 2004), but little is known about the decision processes used by students when they decide to respond to asynchronous communication (Virk, 2004). In a face-to-face course, students can use a variety of criteria to decide whether to interact with one one-another. In the online classroom, students are forced to base their decisions on whether to interact without those cues. In the face-to-face environment, expression is much more detailed (Becker-Beck, Wintermantel, \& Borg, 2005). To understand more about this difference, the foundationalist epistemology was rejected in favor of the interpretivist philosophy of empathic identification. This choice precludes an exact, final, or decisive interpretation of the qualitative data collected in this study. Instead, the interpretations generated from the data analysis represent an insider's view of the intentioniality of online students to 'hit reply.' This research contributes to our understandings of how online learners decide to interact in online discussions. The findings may help online educators understand more about the meanings students ascribe to 'hitting reply' and improve the quality and depth of their online student discussions.

\section{Problem Statement}

Discussion and teamwork in online classes give students opportunities to collaborate in a supportive atmosphere and enrich the learning environment. Learning management systems contain a host of instructional tools such as email, chat rooms, and online discussion forums that facilitate online communication and collaboration. Online collaborative projects provide opportunities for students to organize and facilitate their group working structuressuch as setting boundaries, guidelines, developing relationships and working towards a shared goal (Lou \& Macgregor, 2004). However, providing the instructional tools and venues to exchange dialogue does not ensure that students will be compelled to respond to their teammates' posting, or that the online group will grow in cohesiveness (Murphy, 2004). Murphy cautions that: "such collaboration will not automatically occur simply because peer-to-peer interaction is supported and facilitated" (p. 422).

It becomes increasingly important to understand how and why students make these decisions. Understanding that decision-making will help us foster more effective learning environments and find ways in which learners can maximize online communication effectiveness. As virtual teaming and communicating become increasingly pervasive in the workplace, and as the frustration with unnecessary and frivolous communications increases, it becomes necessary to understand what students perceive as communication worthy of response. Therefore, the research question for this study is: What is/are the decision making process(es) students use to reply to an asynchronous discussion posting?

\section{Theoretical Framework}

Social Presence

One way to examine the degree of online interactivity is through the lens of social presence theory. Social presence Copyright C 2007 Diane D. Chapman, Julia Storberg-Walker, \& Sophia J. Stone 
has been found to enhance and positively influence online social interaction, and is an important factor in building online community (Aragon, 2003; Tu \& McIsaac, 2002). Garrison, Anderson \& Archer (2000) define social presence as the "ability of participants in a community of inquiry to project themselves socially and emotionally, as "real" people (i.e. their full personality) through the medium of communication being used" (p. 94). A concept linked with social presence is immediacy - the psychological distance between communicator and recipient. Online environments with high immediacy behaviors (frequent feedback and response, initiating discussion) may enhance the degree of social presence (Tu, 2000).

For online learners, social presence is the feeling of community experienced in their online environment. The degree of social presence is dependent upon the communication technology and the individual learner's perception (Tu \& McIsaac, 2002). A strong online learning community helps students feel connected, offers a sense of belonging with shared goals, and helps students experience a higher quality learning experience (Ouzts, 2006). Ouzts states that "interaction, participation, and social learning experiences are key factors in promoting connection and lessening isolation among students" (p. 286). In an online environment, the benefits of social presence foster a positive learning environment and facilitates the communication process (Aragon, 2003). Aragon notes that online environments lacking social presence may be perceived as impersonal or un-collegial, and information sharing may be decreased. Thus, a lack of social presence may limit the students' opportunities to connect and positively interact with one another and may play a role in the decision process to reply or not to reply to discussion postings.

\section{Interpersonality and Impersonality}

Since the degree of social presence in the learning environment may impact student response and interaction in online discussion postings, it is useful to consider the social dimension of online student-to-student communication and its role in facilitating discussion. Beuchot \& Bullen (2005) note two vital concepts within this social dimension framework: interpersonality and impersonality, either of which may affect a student's desire to respond to a discussion posting. Interpersonality is defined as "social or personally oriented interaction or information communication aimed at the creation of relationships among participants, while impersonality is task-oriented communication in which information is offered or requested" (p. 68). For example, a student may be compelled to respond if the post requires content information (impersonality) or requires social interaction at the support level (interpersonality), thus building a relationship with another student. Interpersonality is closely linked to social presence, since it is more personally oriented (Beuchot \& Bullen). Both interpersonality and impersonality can be categorized as positive or negative and may affect levels and types of online interaction.

\section{Collaboration}

Social presence is a key element in building an online community of learners and necessary for collaborative work (Conrad, 2002; Garrison, Anderson \& Archer, 2000). Because social presence is linked to interpersonality, and hence relationship building, students with a strong sense of social presence may be considered the "community builders" of an online course. Social presence may be a key element of the online collaboration process and helps to explain how team members can move from the earliest stage of interaction to constructing a shared meaning and achieving shared goals--the true meaning of collaboration (Murphy, 2004). An awareness of how students perceive their and other students' group collaboration experience helps to understand how students build and facilitate collaborative learning environments, how they relate to one another, and the processes they identify as leading to effective online communication. Student perspectives are helpful to understand how to best present oneself online and how to develop "purposive relationships," and thus, work towards shared goals (Murphy).

For instructors and students alike, it is useful to consider the decisions students make when they respond to each other's postings. There may be a connection between social presence and decision to respond, but the connections are not clear. The decisions may be based on the perceived skills that have been suggested as necessary for collaboration, such as interpersonal, group management skills, and inquiry skills (Lou \& MacGregor, 2004). These skills help to move students beyond interaction to reach collaboration. According to Schrage (as cited in Murphy, 2004), moving from interaction to collaboration is a six stage process on a continuum. At stage one, when learners start communicating online together, a basic social presence (interaction) is present. The interactions are then 'enhanced' by a sequence of stages: stage two is demonstrated by articulating individual perspectives, stage three illustrates students reflecting on the perspectives of others, in stage four the students are moving to co-constructing shared perspectives and meanings, stage five finds students building shared goals and purposes and, finally in stage six, the students are producing shared artifacts. These six stages have been identified in previous research; however, not all groups move from interaction to collaboration. Murphy states: "Simple interaction is a necessary prerequisite to full collaboration, but simple interaction may occur without even moving forward to higher levels of collaboration" (p. 423). This means that interaction itself does not cause collaboration; the mystery lies in finding 
the connections between social presence and decision to respond to understand more about collaborative learning. True collaborative learning assumes that knowledge is a consensus among the members of a community and this knowledge was constructed by discussion among peers who reached consensus and agreement (Skiba, 2006).

\section{Research Questions}

The purpose of the study was to understand decision-making processes of students responding to discussion posts. The central research question for this inquiry was 'how do students decide to hit reply?' The question was broken into sub-questions posed to students on a survey instrument: 1 . Describe a situation or two that when you read a posting, you then felt compelled to respond to it. Why do you think you responded to the posting? 2. Describe a situation or two that you did not feel compelled to respond. Why do you think you did not respond to the posting?

\section{Methodology \\ Research Participants}

Students from two master's degree research courses were contacted for voluntary participation in this study. The instructor did not know who chose to participate until after final grades were submitted-the process was explained to the students during the study recruitment phase and was a primary mechanism to ensure participant autonomy. This group of students represented a challenge to gathering meaningful data due to their living in a wide geographic area-from Egypt to Delaware. Consequently, the study could not use the preferred structured interview format (Fontana \& Frey, 2000), and instead relied on structured questions delivered via a survey instrument. The structured interview format was the data-gathering method of choice for two reasons: first, this was an exploratory study, seeking to identify preliminary categories for future development. Second, structured interviews are likely to elicit rational responses to the specific questions. The study focused on the rational decision-making process of hitting reply to narrow the scope of the study - the emotional dimension is relevant but not addressed in this study. Consequently, this study translated the structured interview questions into survey form to meet the geographical restrictions posed by the participant population. This and other study limitations will be presented later.

Data was collected from students in the same course over two different course offerings in successive years. There were a total of 27 students in the two courses, and 21 agreed to participate in the research (10 in the first and 11 in the second). (Due to space limitations, information about the course is not included in this manuscript; interested readers are advised to contact the authors for this data.)

\section{Data Collection Process}

The survey was mailed to students approximately two weeks before the end of the course. Participants were asked to return the survey to a third party — not the instructor - by the last day of class. The survey included several structured questions about the aspects of their online experience for a particular group project, entitled the "Acme Project." This manuscript focuses on two of the questions in the survey pertaining to understanding how students decided to 'hit reply.' The standard 'describe a situation when...' approach was used to allow the participants to elicit self-generated stories. A follow-up question asked 'why,' to better understand how the participants made meaning from their experiences. The questions were:

1. Think about your online communications with your group for the Acme Project. Describe a situation or two that when you read a posting, you then felt compelled to respond to it. Why do you think you responded to the posting?

2. Then, please describe a situation or two during the Acme Project that you did not feel compelled to respond. Why do you think you did not respond to the posting?

\section{Data Analysis Process}

This study adopted a contested position that interpreters can understand the meaning generated from participant responses to structured questions. This study used empathic identification (Schwandt, 2000) as its data analysis approach. This approach assumes "it is possible for the interpreter to transcend or break out of her or his historical circumstances in order to reproduce the meaning or intention of the actor," (Schwandt, 2000, p. 192). While this assumption is open to debate, it has a long history in qualitative research and its origins can be traced back to Dilthey (Hoedekie, 1998). For the purposes of this exploratory study, empathic identification is the most appropriate analysis process because of the data collection mechanism (structured questions on a survey) and phenomenon under investigation (rational student decision making to reply in the online setting). Further, because of these choices, interpreter neutrality is assumed. Thus, unlike more emergent or post-modern perspectives, the positionality of the interpreter is not an issue. Open coding was used to locate themes and categories as they 
emerged in the responses to survey questions. To establish inter-coder reliability (Miles \& Huberman, 1994), three researchers coded the responses independently then met to come to consensus on a final list of themes.

\section{Limitations}

There are several limitations to this study, some of which were hinted at above. First, the study focused on one aspect of experience-rational decision making. Second, the study assumed that neutral interpreters could understand participant experiences. Whether or to the degree which interpreters can be neutral is open to debate. Further, 'understanding' other's experience is also challenged in the qualitative literature. Third, the geographic dispersion of the research participants precluded using the optimal data gathering method-structured interviews. The study translated structured interview questions onto a survey instrument. These limitations suggest that the findings are best understood as one possible way to understand the rational decision-making process, and that more in-depth data gathering and analyses are warranted.

\section{Findings}

\section{Compelling Students to Reply}

To the first question, 'why do you think you responded to the posting,' four themes emerged from the analysis that help to explain why students replied to posts. The four themes are: group process criteria, leadership criteria, social criteria, and judgment criteria.

Group process criteria. Students mentioned they felt compelled to respond to posts that concerned facilitating group process work. Some students responded primarily to posts that related to the specific task at hand. As Glenda noted, "In general, the initial planning postings made me respond in order to advance the work of others." Alice described responding to posts to share initial work. "I did my share of the initial work but once my work was summarily chopped up, appropriated by others, and my questions went unanswered, I more or less, left them to it." One student was compelled to respond only if he felt he could add to the discussion or move the discussion further along. Many of the students said they felt compelled to respond to personal requests. "I responded to postings that asked for information, clarifications, opinions, or requests to gather data." A few felt they had to serve certain functions in the group and responded based on those roles. Alice complained, "My voice of reason fell on deaf ears." "I feel it's my responsibility to make groups work smoothly. I'm a "smoother." I don't like conflict; I like negotiating calmly" said Benita. These comments suggest that students decide to reply if they perceive their post will contribute towards the ongoing process of the project. The comments also suggest that students can be aware of the flow of group process in addition to answering content questions.

Leadership criteria. A large number of students described responding according to actual or self-imposed leadership roles. As Martin noted, "I felt that I needed to respond so that we would not waste a lot of time trying to meet everyone's needs." Some felt they had to respond in order to provide or change the direction of the group. As Patricia described, "there were many instances when individuals really were not sure in which direction to go in the development of their parts." Gabby noted "I felt I needed to step in early to take control of the meetings and set the boundaries/guidelines for the meetings." Some group members described responding to others out of feelings of responsibility. Tanya noted, "As facilitator for Team 1, I felt it was my responsibility to respond to all postings." Other students responded to posts to clarify or coordinate. As John described "I felt the need to initiate conversation to determine whether we wanted the survey to be mailed or online." John described his need to influence the discussion: "As my confidence has grown as an adult, the better a coordinator and leader I've become. I like listening to lots of ideas, and am able to make quick decisions. I'd rather make a bad decision than watch groups languish in indecisiveness." Other students described their needs to serve as motivators for the group. Sally claimed, "I felt a desire to respond to positive feedback because it was encouraging and made me feel more connected- I felt my quick responses seemed to reward the sender." "The template was eye-catching and it captured our plans very well. Thus, I wanted to immediately recognize his efforts," Tabitha described. These comments suggest an additional dimension to decisions to reply beyond group process; these comments incorporate personal responsibility, or a personal need to lead the group forward.

Social criteria. Certain students felt compelled to respond to discussion posts for primarily social reasons. Some wanted to promote group inclusion, such as Sally described, "I felt a desire to respond to positive feedback because it was encouraging and made me feel more connected." Linda agreed, "I felt that we should all give each other feedback." Sally felt that her quick responses rewarded senders. Janice responded to people who she felt had been ignored. "I often respond to students who haven't had a reply yet," she said. Other students responded based on more affective or emotional needs. Laura found, "Most of my posts for this project were either panic questions, 
or supportive statements." Janice claimed that she responded to posts from people she "liked." These comments seem to reflect the interpersonality category articulated by Beuchot and Bullen (2005).

Judgment criteria. Students described several instances where they felt compelled to respond to postings to correct or critique the work of others. John noted, "I felt the need to advise others that these mistakes had been identified and needed to quickly be corrected prior to our presentation." Or as Mark described, "Any compulsion to respond to postings in the Acme Project came when I read things that were either blatantly incorrect, or veering from the track on which I thought the project needed to be." Linda described a situation where her post was met with negativity. "I commented on her paper by inserting some comments in the original document and then posting the document. I got the impression that she was offended rather than able to take constructive criticism." Charles used the instructor's example to support his post. "I felt compelled to tell her what I thought should be brought into alignment with the example." Other members felt the need to respond in defense of their own work. As Jane described, "I posted to the group comments that I hoped would allow my work to remain as close as possible to what I created." This was supported by Lolita who said, "I felt compelled to write about why [my contributions] were deleted and why the introduction was only $21 / 2$ pages long." These comments suggest that students decided to post to correct or defend previous work. The judgment of the students concerns two perceptions; perception that a fellow student posted something incorrect, or a perception that one of their own posts was unjustifiably critiqued.

\section{Compelling Students to Not Reply}

To the second question, namely, 'why do you think you did not respond to the posting?' Four themes also emerged. These four themes were applicability, judgment, leadership, and social criteria.

Applicability criteria. Students said they did not respond to posts they felt were directed at others or they felt were not applicable to their work. As Glenda noted, "I did not respond to correspondence between two other group members." Tabitha said, "If there were postings in which two or more members were trying to make a decision, I might hold off on jumping into the conversation." "I did not respond to postings that referred to sections that I was not involved with" said Brenda. "I didn't think it was necessary for me to micro-manage those sections I was not already working on" reported Alan. Mark claimed, "If I had comments or the post was applicable to my work, then I responded; if not, I did not clutter up the discussion area." These comments suggest that students decided not to post when they perceived that their thoughts were not applicable. Applicability in this context seems to be a two dimensional construct. Work applicability is concerned with whether or not the postings were directly relevant to the student's own work (e.g., the work assigned to her/him in the group project). On the other hand, process applicability is represented by comments such as "I did not respond to correspondence between two other group members." Note that process applicability does not contain words suggesting a concern for the topic of the course; rather, process applicability is concerned about the flow of information between people.

Judgment criteria. Many students described situations where responding was not of value for either themselves or their group. They tended not to reply to posts when they felt they could not add information. "I contributed when I thought I could add beneficial and substantive information. I didn't want to respond or participate in conversations if I did not have anything to say that could facilitate the conversation, noted Tabitha. Brenda agreed, "[I did not respond to] postings that asked for comments and I had no worthwhile comments to make." Mark added, "If a subject had been discussed ad nauseum then there was no need to keep belaboring the point. Also, if someone asked a question that had already been answered, I typically ignored those as well." Patricia did not respond to posts from certain people. "I did not respond to multiple postings as to people being sorry for not being as involved, or getting started at the beginning,....I have little patience for individuals who put off projects until the last minute." Other students attributed their lack of response to a need to avoid chatter or nuisance posts. As Sally described, "The constant chat that I didn't feel apart (sic) of did not get responses." Charles had somewhat the same criteria. "I have seen proliferation of semi-useless posts that I have had to weed through and frankly do not have enough words or energy in me to respond to everything!" "I have found throughout the online program that it takes a lot of time just to look up the postings of others, and I wanted to keep my own "nuisance" postings to a minimum" commented Laura. Matt said "The most frequent time that I did not respond was if I agreed with someone, and didn't feel exactly like posting a one line "I agree!" These comments suggest that deciding not to post is spawned by a number of different negative judgments, ranging from 'semi-useless posts' to 'limited patience for...' to 'huge pet peeve of mine...' On the survey, emotional language was used in the 'deciding not to' than the 'deciding to' post, and is reflected here. From this data, it appears that the decision not to post can be made based upon value or merit; further, those posts lacking value or merit are judged and thought of in pejorative ways.

Leadership criteria. Some students attributed their lack of response to a lack of need to provide leadership. Laura said, "Generally, if I agreed with someone, and my opinion or approval wasn't required, I didn't contribute." "I did stay out of it if it was clear folks were working well with other people on the team and didn't need support or 
decision making completed" claimed Benita. Jane agreed, "If I believed that the project was headed towards an acceptable level of achievement, I did not respond to general postings." Linda gave reasons for not providing leadership. "I did not respond to the first several posts about setting up the group. Although I am a pretty assertive person, I am not comfortable in the spotlight. I can be a leader as long as I am not the designated leader." Charles also did not reply to posts about logistics. "It was a lot of work to figure out what your assignment was supposed to be and how you should approach it. Quite frankly, I was spending a lot of time doing that for my assignment and didn't feel like doing the necessary research to develop an approach for the other assignments." These comments suggest similarities about deciding to post. There may be a meta-cognitive understanding of group process, going beyond the content or topic of the activity. These comments suggest that some students feel the need to keep the process on track, reply when people needed support, and view their posts as catalysts for future project completion.

Social/personal feelings criteria. Other students did not reply to posts for reasons that were social or personal in nature. One student told us that she did not respond to posts from people she did not like and people who "don't know what they're talking about." Alice described how she felt personally devalued during the course of the project. "My suggestions were not accepted. At the beginning of the project, I was an enthusiastic participant. However, the situation quickly deteriorated and I found myself responding to fewer and fewer postings." The feeling of being devalued is not the only personal feeling that emerged. Sally said "I felt excluded in many ways because I hadn't had responses to my questions- yet knew I had to contribute. It was the group member that made me feel welcome and shared my concerns that responded to most frequently." These comments suggest that deciding not to post may be connected to personal feelings of like/dislike and feelings of being devalued or excluded. These negative feelings seem to be generated by two mechanisms. One mechanism is understood as liking or not liking, or degree of affinity. The other mechanism has to do with the student's ideas being accepted by peers. When students to not reply to a post, or they do not accept an idea in a post, these situations send a strong signal to the student originating the post. The signal can trigger the feeling of 'exclusion' or 'devaluation.'

\section{Discussion}

The findings above confirm that Beuchot and Bullen's (2005) social dimension framework is an appropriate heuristic to understand more about why students reply to each other in the online environment. The decision criteria of applicability, group process, and leadership fall primarily in the 'impersonality' dimension on online communication. The decision criteria of social and judgment are aligned with the 'interpersonal' dimension framework. The judgment, leadership, and social criteria are evidenced in the decision to post as well as not to post. This is an important finding because it links social presence with student decision making in the online asynchronous environment. Students decide when and how to post, and previous studies have examined how the posts create a social presence. This study adds another layer to social presence-this study examined what happens before social presence is created in order to understand the factors and decision processes that eventually are manifested in online social presence.

\section{Impersonality}

In Beuchot and Bullen's (2005) framework, this study found evidence of impersonality. This task-oriented communication was suggested when students requested information, or feedback was needed to facilitate the group process work. When group process work required informative postings, clarification, feedback, or responses that furthered the work of the group, students decided to respond. Students also decided to respond to posts that offered good ideas, information or those that requested reviews of material or critique of ideas, or to correct blatant errors in group project work. Students decided to respond to posts that required that boundaries and guidelines be set for the team; to ensure effective use of time management; to make things work smoothly; and to facilitate coordination of team efforts. This ensured that other group members did not 'derail' the process and prevented a group floundering with indecision. Students also decided not to post for impersonal reasons. If a student did not feel he/she could facilitate the conversation to move forward, because the student may have his/her own questions or a level of uncertainty, the student did not respond to postings. Students did not post if the discussion did not concern their role in the project, and students did not post to a discussion between other students.

Analyzing the impersonal decision-making criteria, and contrasting them with the interpersonal decisionmaking criteria, exposed an interesting characteristic of the decision-making process. As described below, the study suggests the decision-making process of posting blurs the distinction made by Beuchot and Bullen (2005) between impersonality and interpersonality. This blurring occurs when students perceive what can be classified as an impersonal post as being irrelevant, redundant, or stupid - this perception generates negative feelings. In essence, what is perceived as a bad topic or content posts (impersonal) generates bad feelings (interpersonal). It appears that 
impersonal posts can generate interpersonal responses. This was a strong, repetitive theme in the survey responses. However, there was a much weaker suggestion that bad process posts (impersonal) generated bad feelings (interpersonal). Process posts are described above as facilitation questions, clarifications, feedback requests; in general, process posts were focused on moving the project forward. Consequently, this study suggests that the decision-making processes for process-type posts may be different than the decision-making processes for topic or content-type of posts (see Table 1). The decision-making process for replying to process posts seems to stay in the impersonal dimension; students stay on task and decide to reply based on logical or objective criteria. However, deciding to reply to content or topic posts does not seem to use the same criteria. Deciding to reply to a content or topic post is more likely to involve decision making based on emotional or subjective criteria. The influence of personal feelings on the decision making process are described below.

Table 1. Dimensions of Decision Making

\begin{tabular}{|l|l|l|}
\hline Communication Dimension & \multicolumn{1}{|c|}{ Type of Post } & \multicolumn{1}{c|}{ Primary Decision Making Criteria } \\
\hline Impersonal & Group process & Decision sequence stays on task: logical, objective \\
\hline Impersonal & Content/topic & Decision sequence stays on task: logical, objective \\
\hline Interpersonal & Group process & Decision sequence stays on task: logical, objective \\
\hline Interpersonal & Content/topic & Decision sequence influenced by feelings: emotional, subjective \\
\hline
\end{tabular}

\section{Interpersonality}

Like the above discussion of impersonal posts, students also decided to respond or not to respond as described in Beuchot and Bullen's (2005) interpersonality dimension of social presence. This dimension represents more social or personal decision-making criteria. Evidence of this dimension includes initiating conversations, motivating the group to action, or offering support to other group participants throughout the project work cycle. Responses of this type suggest a supportive group member who wants to reply immediately to signal affirmation. Some students offered supportive statements to the team, such as offering one's own skill strength to the team, or recognizing a team member's efforts were interpersonal posts of a positive nature. The decision-making processes of these types of posts included deciding to post specifically to posts that had no reply (an inclusive influence on deciding to post), deciding to post quickly (a temporal influence on deciding to post), and deciding to post affirmations or encouragement (a positive influence on deciding to post). The findings suggest these decisions are made to improve the good feelings and collaborative structure in the online community.

Students also decided not to post for personal reasons. As described above, students' perceptions of an impersonal post as without merit, not having value, or being wrong can trigger negative feelings that are then carried over to their decision making. The replying student is thus more likely to reply with a negative interpersonal post. For example, one student, after reading a 'bunch' of 'semi-worthless posts,' decided not to post because he equated more postings as 'beating a dead horse.' There was strong and multiple evidence that impersonal content/topic posts often triggered these negative feelings through survey responses such as other 'students don't know what they're talking about,' 'looking amateur,' 'nuisance posts,' ignoring posts 'asking the same questions that were answered before,' and describing certain posts as 'a pet peeve of mine.' The word choice and phrases used to describe decisions to not post were more personal and inflammatory than the words and phrases to describe decisions to post. Further, topic and content posts generated more personal, and inflammatory, word choices and phrases than processtype posts when describing the decision process.

\section{Implications for HRD}

This exploratory study offers HRD researchers and practitioners a multi-faceted understanding of online social presence by exploring the decision making process of students. By examining these decisions HRD researchers and practitioners are more able to recognize and improve how social presence is generated and how groups move from communicating to collaborating. Although we have seen that students may decide to post or not from both social dimensions (e.g., impersonal and interpersonal), high performance and collaborative group work require communication to move from individual effort to the level of group effort-this intergroup need develops learner-tolearner supportive interactions in teamwork efforts (Murphy, 2004). When some students decide not to respond to teammates because of perceptions that are personality based, the group working structure may not be as inclusive and its team members may not be working towards a shared goal (Lou \& Macgregor, 2004). Basing decisions to post on personal reasons may prevent development of shared understandings. Research has shown that successful online collaboration implies that students construct shared knowledge while developing "purposive relationships," working together to achieve the shared goals of the team (Murphy, 2004). 
Developing a collaborative working structure, developing shared goals, and reaching shared understandings are necessary for high performing online teamwork. Because this study suggests that interpersonal decision making may negatively impact these important group characteristics, HRD practitioners have a new focus for intervening in online environments. Practitioners can develop interventions aimed at decreasing the frequency of negative interpersonal decisions. These interventions may include encouraging reflection about the decisions to post, developing a guide sheet or checklist that exposes 'unhelpful' decision-making processes, and monitoring the online environment to target when personal posts emerge. Along the same lines, practitioners can focus interventions designed to increase the frequency of positive interpersonal decisions. Practitioners can encourage more processtype postings by demonstrating the value of process at the beginning of group work. As students become more able to use less subjective impersonal criteria to decide when to reply to process posts; it is likely that those skills will enhance the effectiveness of responding to content posts. In addition, HRD scholars may want to replicate or extend the findings of this exploratory study to understand more about posts that trigger decision making influenced by emotion and subjectivity..

\section{References}

Aragon, S. R. (2003). Creating social presence in online environments. New Directions for Adult and Continuing Education, no. 100, 57 - 68.

Becker-Beck, U., Wintermantel, M., \& Borg, A. (2005). Principles of regulating interaction in teams practicing faceto-face communication versus teams practicing computer-mediated communication. Small Group Research, $36(4), 499-536$.

Beuchot, A. \& Bullen, M. (2005). Interaction and interpersonality in online discussion forums. Distance Education, 26(25), 67-87.

Conrad. D. (2002). Deep in the hearts of learners: Insights into the nature of online community. Journal of Distance Education, 17(1). Retrieved March 20, 2006 from: http://cade.athabascau.ca/vol17.1/conrad.html

Fontana, A. \& Frey, J.H. (2000). The interview: From structured questions to negotiated text. In N.K. Denzin and Y.S. Lincoln (Eds.) Handbook of Qualitative Research, p. 645-672. Thousand Oaks, CA: Sage.

Garrison, R.D., Anderson, T. \& Archer, W. (2000). Critical inquiry in a text-based environment: Computer Conferencing in Higher Education. The Internet and Higher Education, 2(2-3), 87-105.

Hara, N., Bonk, C.J., \& Angeli, C. (2000). Content analysis of online discussion in an applied educational psychology course, Instructional Science, 28(2), 115-152.

Hoedekie, N. (1998). In the light of shadow. Paper presented at the 4th Annual Qualitative Methods Conference: September 3, 1998, Johannesburg, South Africa. Retrieved November, 7, 2006 from http://www.criticalmethods.org/shadow7.htm

Kanuka, H. \& Garrison, R.G. (2004). Cognitive presence in online learning, Journal of Computing in Higher Education, 15(2), 30-49.

Lou, Y. \& MacGregor, S. K. (2004). Enhancing project-based learning through online between-group collaboration. Educational Research and Evaluation, 10(4-6), 419-440.

Miles, M.B. \& Huberman, A. M. (1994). Qualitative data analysis, $2^{\text {nd }}$ ed., Thousand Oaks, CA: Sage Publications.

Murphy, E. (2004). Recognising and promoting collaboration in an online asynchronous discussion. British Journal of Educational Technology, 35(4), 421-431.

Ouzts, K. (2006). Sense of community in online courses. The Quarterly Review of Distance Education, 7(3), 285 296.

Pelz, B. (2003). (My) three Principles of effective online pedagogy. Journal of Asynchronous Learning Networks, 8(3), Retrieved 11/6/2006 from http://www.sloan-c.org/publications/JALN/v8n3/v8n3_pelz.asp

Schwandt, T.A. (2000). Three epistemological stances for qualitative inquiry: Interpretivism, hermeneutics, and social constructivism. In N.K. Denzin and Y.S. Lincoln (Eds.) Handbook of Qualitative Research, (pp. 189214). Thousand Oaks, CA: Sage.

Skiba, D. J. (2006). Collaborative tools for the net generation. Nursing Education Perspectives, 27(3), 162-163.

$\mathrm{Tu}, \mathrm{C}$. (2000). On-line learning migration: from social learning theory to social presence theory in a CMC environment. Journal of Network and Computer Applications, 23, 27 - 37.

Tu, C. \& McIsaac, M. (2002). The relationship of social presence and interaction in online classes. The American Journal of Distance Education, 16(3), 131 - 150.

Virk, B. (2004). A balancing act: Improving student online discussion participation. International Journal of Instructional Technology and Distance Learning, 1(6), June 2004. Retrieved November 11, 2006 from http://www.itdl.org/Journal/Jun_04/article08.htm 